\title{
İnsanlığın Çözüp Bitirilemeyen Sorunu: Amaçsal ve Araçsal Akıl (Akıl ve Zekâ İkilemi)
}

Mustafa Aydın

\section{Giriş}

Akıl, insanın özlük alanının en önemli unsurlarından birisidir. Hayvanların aklı yoktur, ancak insandaki akla karşılık onun yerine içgüdüsel donanımları vardır. Dünden bugüne akıl üzerine çok şey söylenmiş, akıl, insan aklının en önemli konularından birisi olmuştur. Bilmede bir süje olan akıl, kendi üzerine katlanıp bizzat kendisini bir obje olarak ele almıştır. Şüphesiz en sorunlu bilgilerden birisi süjenin bizzat kendisi hakkında verdiği bilgidir. Hele bu konuda referans sayllı lâyüs'el (sorgulanamaz) görülürse yanılgı kaçınılmaz olmuştur. Akıl, Rönesans ve özellikle 18. Yüzyll Aydınlanma düşüncesinden bu tarafa felsefenin başat konusu olmuş, bu alanda geniş bir literatür ortaya çıkmıştır.

Genelde bu yazım dünyası, belli bir paradigmaya dayanmaktadır. Tartışmaya gerek duyulmayan ve Aydınlanma'dan beri yürürlükte olan bu paradigma şöyle ifade edilebilir: "Akıl, doğru bilginin biricik kaynağıdır. Ancak bu görevi yerine getirebilmesi için özgürleştirilmesi gerekir. $\mathrm{O}$, özgürlügünü sınırlayan ve dolayısıyla doğru düşünmesini engelleyen olgular olan gelenek ve dinin ipoteğinden kurtarılmalıdır. Bu sağlanabildiği oranda başarı sağlar. Özgürleştiği oranda modern olarak nitelendirilen bir kültür ortaya koyabilmiş olması bunun en açık delilidir..." Şüphesiz dünden bugüne yeterince sesini duyuramamış olsa bile bu tezi eleştiren düşünür ve yazarlar olagelmiştir. 
Elimizde bu eleştiri kutbuyla ilgili bir eser bulunmaktadır: "Dünyevi Aklın Buhranı-Rasyonalizm ve Modernite Eleştirileri” adını taşıyan eser Alper Gürkan tarafından kaleme alınmış, Büyüyen Ay Yayınları tarafından basılmış 208 sayfalık bir kitaptır. Eser üç bölümden oluşuyor: "Rasyonalizm ve Modern Felsefe", "Kültür ve Sanatın Aklileştirilmesi”, "Modernlik, İdeoloji ve Toplum”. Genel olarak bilgi sorunlarına değinen birinci bölüm, dünyevi akla ulaşmak üzere bilginin sekülerleşmesini ele almaktadır. Yazarımız Gürkan, burada bilgide hakikatin rasyonellikten geçtiğini, bu konuda ölçü olarak alınması gerektiği ileri sürülen nesnelliğin bu yolla sağlanabileceği iddiasını ele almakta, bunun sağlanamadığını, buradan esaslı bir nesnellik krizinin doğduğunu göstermeye çalışmaktadır. Kitabın ana teması veya tezi olan kriz de burada yer almaktadır. Çünkü diğer bölümler ciddi bir şekilde rasyonalitenin doğurduğu sorunlara değinmekle birlikte, bu bölümde krizden ziyade her yerde etkin ve egemenliğini gösterebilen bir rasyonalite sürecinden söz etmektedir.

Kitabın yarısını oluşturan ikinci bölüm, rasyonalitenin kültürü, onun değişik alanlarını nasıl rasyonalize ettiğini gayet başarılı bir biçimde göstermektedir. $\mathrm{Bu}$ çerçevede, bizzat kültürün kendisi, dil, sanat, ideoloji, iktidar, ahlak, olgularının nasıl aklileştirildiğini ve tabii nasıl sorunlu hale getirdiğini göstermektedir. Ancak burada rasyonel aklın bizzat kendisinin sorununa ve belki daha doğru bur ifadeyle krizine pek vurgu yapilmamaktadir.

Üçüncü bölüm, ikinci bölümün temel esprisi içinde yazarımızın ifadesiyle dünyevi aklın, yine farklı alanlarda, kendinin başarı saydığı ama sonuç itibariyle ciddi sorunları olan endüstriyel toplumsallık, insanın mekanizm kıskacında kalması, sosyoloji sayesinde toplum üzerinde insan onuruyla alay edercesine sürdürülen bir toplum mühendisliği, yine medya ile insan aklını hafife alan icraatlar gayet iyi ifade edilmiş. Kitabın içeriği bize üç önemli soru üzerinde durmamız gerektiğini gösteriyor. Bunlar: Akıl ne idi, ne oldu? Dünyevi akıl nedir? Bu akıl tipi ne gibi sorunlar doğurmuştur ve bizzat kendisinin yaşadığı kriz nedir? Biz bu değerlendirme yazımızda örnek alanlardan daha çok, eserin tezi olan dünyevi akıl ve sorunları üzerinde durmak istiyoruz.

\section{Aklın Sınırları ve Akıl Tipleri}

İşin gerçeği orada duran, insanın kafasında ışıldayan ve her zaman doğruyu bilen ve gösteren bir ontolojik akıl yoktur. Akıl insanın bir iç algılama yeteneğidir. Dekart gibi bazı rasyonalistler, aklın her şeyi çözebileceğini ileri sürmüşler, bilgisizlik veya yanlışın, aklın izafiliği veya yetersizliğinden değil, iyi kullanılamamasından kaynaklandığını iddia etmişlerse de bu yargı doğru değildir. Çünkü bu yetenek, 
aşkın-içkin farklı yönlendiricilere, insanın içinde bulunduğu toplumsal şartlara, kişinin beklentilerine göre bir sonuç ortaya çıkarmakta, bir karara varmaktadır. Dolayısıyla ortaya konan akli veriler de birbirinden farklıdır. Aslında pek çok akıl yok, pek çok akli süreç vardır ve bundan dolayı da aynı konuda farklı doğrular vardır. Bunun farkına varan insanlar, söz konusu farklılığa bakarak birçok akıl türü olduğunu varsaymışlar ve bu konuda yaygın tipolojiler oluşturmuşlardır. Yani buna göre bir akıl yok, pek çok akıl tipi vardır: Araçsal akıl, amaçsal akıl, seküler akıl, dünyevi akıl, rasyonel akıl, üst akıl, ortak akıl, sağduyulu akıl, akledici akıl gibi. Hatta rasyonel akıl bile kendi içerisinde bir hayli farklılıklar gösterir. Mesela sonuç itibariyle akıl üstüne oturan Hıristiyan felsefesinin realist akılcılığ ile 17. yüzyıl Kartezyen felsefesinin spekülatif akılcılığı ve 18. Yüzyıl Aydınlanmacılığının nominalist akılcılığı arasında ciddi farklar vardır.

Gerçekten de aklın yöneltildiği yere göre farklı akıl(cılık)lar ortaya çıkmıştır ki bunun en tipik olanı Aydınlanmacı Kant'ın kültüre yönelttiği kurgucu akılcılıktır. Bu içkin kurgulama dışındaki her yol, akıl dışı sayıldı. Aslında aklın farklı yönlerini kapatan bu akılcılık bir tür akıl dişılıktı. Çünkü burada, orada duran bir mutlak gerçeklik yok, şartlara göre oluşturulan bir açıklama vardı. Buna göre, mesela demokrasi doğal aklın gereği bir sistem değil, sınai kapitalist düzenin öngördüğü bir sistemdi ki bu bir rasyonaliteden ibaretti.

Esasen bütün akıl kategorileri iki grupta toplanabilir: Akılc1 akıl ve akledici akıl. Araçsal, seküler gibi kategorilerin büyük bir kısmı akılcı (rasyonel) akıl grubuna girmektedir ki yazarımızın dünyevi akıl dediği tip de bu grubun bir başka adıdır. Rasyonelin karşıtı olarak kullanılan akledici akıl hikmetle yönlendirilmekle birlikte, insan doğasına uygun olarak çalışan akıldır. Amaçsal akıl, ilk bakışta anlamlı gözükmekle birlikte, bir hayli kaypak bir anlam ifade ediyor. Bu akli yapının temel özelliği, birilerinin yararını amaçlıyorsa araçsal akıldan bir farkı yok demektir. Özel bir çıkara hizmet etmeyen anlamında ise bir masumiyet ifade etse de orada duran insani özlük alanımızın geliştiricisi bir akıl anlamını taşımaktan uzaktır. Üst, ortak ve sağduyu akılları kişisel çıkarları aşmış bir akıl anlamını taşımakla birlikte, hakkı hakikati ifade etmemiş olabilir. Sonuç olarak eşyanın hakikatine uygun, Hakk'a (Allah'a) dayalı, insan fitratına uygun bir akıl, akledici akıldır. Asıl sorun da akleden bir aklın yerine felsefede daha çok rasyonalizm olarak bilinen aklileştirici bir aklın ikame edilmesidir. Yazarımıza göre dünyevi akıl, insanı ve anlamını, dünya yaşamını merkeze alma zaafını taşıyan, tarihsel olarak Rönesans'tan itibaren ortaya çıkmış bir akletme modelidir (s. 9) ve bu açıdan "kitabın amacı da dinî, sanatsal, kültürel, ekonomik ve siyasi alanlarda ortaya çıkan sapma ve tahrifatı görünür kılmak ve böylece geleneği yeniden görebilme imkânı sağlamaktır". 
Batı düşüncesinde, Rönesans'tan beri, aklın çalışmasına müdahale edilmek ve yeniden kurgulanmak isteniyordu. Bu düşünce, Aydınlanma'da doruk noktasına ulaştı. Aydınlanmacı Kant'ın ifadesiyle akıl, din ve geleneğin ipoteği altındaydı ve bundan kurtarılması gerekiyordu. Aklın aşkınlıklardan arındırılması için yoğun bir mücadele verildi, akıl içkin kurallarla donatıldı ve böylece gözetim ve denetim altına alındı. Bu ifadelerden de anlaşılacağı üzere, akıl üzerinde yapılan bu operasyon bir tür sekülerleştirme hareketiydi ve bunda da bir hayli başarılı olundu. Hareketin adı aklın özgürleştirilmesi idi. Ama işin gerçeği, özgürleştirme adına akıl bir yerlerden koparılırken bir başka yere bağlanıyor, akıl için asıl kölelik yeni başlıyordu. Çünkü kadim kültürlerdeki bağlarından koparılan akıl, egemenlerin kurduğu dünyada bu düzenin araçsal yapısını oluşturuyordu. İnsan, içinden kolayca kalkamayacağı bir boyunduruk altına giriyordu. İşin gerçeği, asıl kölelik zihnî köleliktir, insan bedensel kölelikten daha kolay kurtulabilir ki prangaya ihtiyaç kalmayan bir dönem başlayınca zincirler boşa çıktı; ama akıllara takılan pranganın biteceği gözükmüyor. Çünkü ekonomi çıkışlı mevcut modern kültür geri dönüşlü bu dünyevi aklı hep yeniden inşa ediyor.

Yaygın ama eksik bir kanaate göre ekonomiden siyasete, dinden sanata tüm kültürel oluşumları dünyevi akıl üretmiştir. Bu alanda yaşananlar eksiğiyle fazlasıyla onun eseridir ki A. Comte, ünlü “Üç Hal Yasası”sında, sadeleştirilmiş bir anlatımla, insanlık çağlarının akıl tiplerine göre değişip dönüştüğünü iddia etmişti. Yani buna göre dinsel akıl bir dinî toplum, pozitif akıl bir pozitif toplum ortaya çıkarıyordu. $\mathrm{Bu}$ formül daha sonra sosyolojinin mutlak geçerli formülü oldu; her şey bir biçimde toplumun, onun toplumsal bilincinin, akli yapısının bir yansımasıydı. Bu formülle yapılan açıklamalara göre rasyonel akıl her şeyi belirleyip götürmektedir.

Rasyonalite, mevcut kültürün gizil bir meşrulaştırımını da ihtiva ediyor. Yani bütün bunlar "nihai dayanağımız olan ve kendisinden asla şüphe edemeyeceğimiz aklımızın bir eseridir, bunun itiraz edilebilecek bir yanı yoktur”. Hâlbuki bu akıl da sonuç itibariyle bir yığın yanlışlığı içeren mevcut kültürel şartların bir ürünüdür. Yani bu ilişki karşılıklıdır. Batı'da son iki yüzyılda ekonomik, sosyal, siyasal, fikirsel oluşumlar bileşkesinde ortaya çıkan rasyonel akıl, geri dönüşlü olarak kendisini var kılan şartları yeniden kurgulayıp inşa etmektedir. Yani orada duran bağlarından kurtarılıp azat edilmiş bir akıl yoktur. Aksine akıl, pek çok bağlayıcı etkenlerin altında kendine özgü diyebileceğimiz bir görüşü olmayan, yüklenen paradigmaların, verilen malzemelerin içinde siparişe uygun üretimlerde bulunan edilgin bir yeteneğimizdir.

$\mathrm{Bu}$ arada bir gerçeğin altı özel olarak çizilebilir: Modern kültür adına olup bitenlerin önemli bir kısmı önceden öngörülen şeyler değildir. Bu öngörülmeyen şeyler, sadece terör gibi salt olumsuz durumlarla sınırlı değildir. Mesela inşa etmekle 
çok övündüğü bireyselliği alaşağ1 eden kitlesellik de bu öngörüler arasında yoktur. Hatta olup bitenlerin önemli bir kısmı, geleneksel kültüre ayak uyduramayışın bir sonucudur. Mesela 19. yüzyılda cinselliğin önünün açılması, bu uyumsuzluğun suç olmarktan çıkarılması düşüncesinden kaynaklanmıştı. Bu bir yanılgıydı, ama modernite daha sonra doğrunun bu olduğunu ilan etme yüzsüzlüğünü gösterdi.

Yazarımız burada, son birkaç yüzyılda Batı'da oluşmuş dünyevi aklın yapıp etmelerini farklı alanlardan seçtiği örnekler üzerinden yeterince açıklamış bulunmaktadır. Mesela bunların başında, insanın doğa üzerindeki etkinliği gelmektedir. Aydınlanmacıların ifadesiyle, vahşi doğaya bir gem vurulmuştur.

\section{Aklın İlkelerden Soyutlanması ve Akledici Akla Karşı Rasyonel Aklın İnşası}

Dünyevi akıl, karakteristiği bakımından seküler olarak nitelendirilmektedir. Tabii buna göre de modern kültür dine bir tavır koyma üzerinden bir gelişme göstermiş oluyor. İddiaya göre, bunun en somut şekli de aklın din bağlarından kurtarılmasıdır. Aslında bu yargı, bize bir gerçeği anımsatıyor. Bu gerçek, insan doğasının bozulmadığı dönemlerde aklın aşkın ilkelerle çalıştığı gerçeğidir. Aklın egemen paradigmalara, sırf birilerinin çıkarına çalışmaması için belli dayanaklarının, bir başka deyişle sabitelerinin olması gerekiyordu ve tabii vardı. Bu sabiteleri koyan Allah'tır. Aklın herkes için doğru, herkes için geçerli bir noktada çalışması için ahlaki, insani bir çizgide tutulması gerekir. Hakikat, adalet, tevhid gibi ilkeler akıl için gerekli ilkelerdir. Bu bağlayıcı ilkelere uygun düşmediği zaman akıl zoolojik bir yetenek haline gelir ki bunun adı zekâdır.

Aliya İzzetbegoviç’in de isabetle belirttiği gibi, işlevsel olarak akla çok benzemesine rağmen zekâ akıl değildir. Zekâ yalnızca insana has bir donanım da değildir. Hayvanlar da az veya çok zekidir. Bu, canlının varlığını sürdürmesi için çıkarını, yararını gözetmesini sağlayan, çevresini tanıyıp kurgulayan, verimlendiren bir yetenektir. Hayvanlar için bu genelde içgüdü olarak nitelendirilmektedir. Tabii ki insanın zekâsı daha bütünlüklü ve daha gelişmiş bir içgüdüdür. Hayvanlar bu özellikleriyle insanı hayrete düşüren harika yetenekler sergilemektedir.

Zekânın akıldan önemli farklarından birisi, zekânın ahlaka karşı kayıtsız oluşudur. Zekâ o konuda en yarayışlıyı bulur ve gerekçelendirir, en ahlaki olanı değil. Bunun için en yetenekli hayvanlar bile ahlaklı değildir. Çocuklar büyük çapta henüz zoolojik özellikleriyle yaşadıklarından dolayı ahlaki bir tavır koyma peşinde değil, zekâ gösterisindedirler. Aklın özgürleştirilmesi iddiasıyla yola çıkan ve aşkın bağları koparan modern kültür, insanı zekâsıyla hareket eden zoolojik bir varlık 
haline getirmiştir. Bir başka deyişle özgürleştirilen akıl, akıl olmaktan çıkıp basit bir zekâya dönüşmüştür. Buna göre fedakârlık bir akılsızlık, daha doğru bir ifadeyle bir zekâsızlık, kafanın çalışmaması halidir.

Aslında rasyonel (veya aklileştirici) akıl, fazlaca geliş(tiril)miş bir zekâdır. İnsan ve toplum lehine kurgularla uğraşır, hikmeti bir özellik taşımaz. Onun için özellikle Dekart'tan bu tarafa rasyonalizm hükmi dünyamızın değil, fiziksel dünyanın yasalarını ihtiva eder. Kâinat kitabının matematikle kurulduğu görüşü bu yargımızın en önemli argümanıdır. Fiziksel dünyanın algılanması noktasında bu görüş yanlış değildir. Yanlış olan, tüm insani bilginin tek yanlı bir bilgiye indirgenmesidir. Kur’an'da şöyle denir: "Onlar bu dünya hayatının sadece dış yüzünü bilirler, ebedi olan ahiret ile ilgili bir bilgileri yoktur." (Rûm/7). Yazarımızın da belirttiği gibi rasyonalizm, zihinsel olmayan gerçekliğe ya da aşkın bir hakikat fikrine yabancıdır (s. 19). Çünkü akledici akıl olmaktan çıkarılmıştır. Eğer rasyonalite ile bir aşkın hakikatin keşfine ulaşılmışsa bu, o konuda rasyonalizmin aşıldığı, akledici akla başvurulduğu anlamina gelir.

Özgürleştirilmesi adına asıl referanslarını kaybeden akla ayaklarını basacağı bir yer kalmamış, dengesini kaybetmiştir. Bu dünyevi bilgi bile her zaman gerçekle örtüşmemiş, ister istemez spekülasyona, kişisel kurgulara dönüşmüştür. Bu durum rahatsızlıklar doğurmuş, ama o bunları kendi imkânları içinde çözememiştir. Bilindiği üzere, bu çözüm girişimlerinin en ciddilerinden birisi fenomenolojik çıkıştır. Fenomenoloji, varlığın, mevcut ilkelerden hareketle değil, hali hazırda var olan fenomenlerden hareketle bilinebileceğini ileri sürmüştü. Redüksiyon adını verdiği bir yöntemle mevcut bilgi parantez içine alındığında bunun dışında kalan fenomen bizim aradığımız bilgi idi. Yani böylece aklın özgürlüğü adına ortaya çıkmış spekülasyon aşılmış olacaktı. Hâlbuki fenomenlerden çıkarılan bilgi, sonuç olarak yeni bir kurgulamadır ve bundan kurtuluş yoktur. Olması gereken şey, aklı, fenomenlerin yukarısında yer alan bir mutlak hakikatin yol göstericiliğine ve denetimine vermektir. Herkesin işine yarayan ve kimsenin aleyhine kurgularla uğraşmayan bir akıl için yapılacak iş, onu dayanaklarından koparmak değil onu doğaüstü bir kaynağa bağlamaktır. Şu bir gerçektir ki dayanılan değerler ne kadar fiziksel dünyadan koparılıp doğaüstüne bağlanabilirse o nispette çıkar üstü hale gelebilir. En üst hakikat/ değer tek Allah inancıdır. Tevhidî bir inanç, hiç kimsenin özel olarak yararına veya zararına değildir. Ama değer ve ilkeler İzzetbegoviç’in deyimiyle semadan koparılıp arza indirildikçe birilerinin yararına veya zararına hale gelir. Mesela küreselleşmiş olmasına rağmen aşkın bir dayanağı bulunmayan demokrasi kendini türeten sınai kapitalist dünyanın daha çok işine yaramaktadır. Yani akıl ne kadar dünyaya indirilirse o kadar yanlı ve sorunlu hale gelir. 
$\mathrm{Bu}$ çerçevede üzerinde çok durulan bilginin sekülerleşmesi her ne kadar onun kutsallıklardan koparılması anlamına gelmekteyse de kanaatimce içkinleştirilmesi daha öncelikli bir durumdur. İkisi de aynı sonuca yönelik olmakla birlikte, aşkın olandan bağları koparmakla içkine tutunmak farklı şeylerdir. Dünyevi akıl, kutsalla bağlarını koparmaktan daha fazlasıyla içkine indirilmiştir. Onun için özellikle Batı'da akıl bağlamında ilişkisi koparılan kutsallar çok belirgin değildir, ama kurgunun içsel dayanakları barizdir. Mesela akılsal kurgunun en önemli dönemi olan Aydınlanma salt kutsala açılmış bir savaş değildir. Eserde de alıntılandığı üzere Aydınlanma, 18. yüzyılda baskıcı dinsel dünya görüşüne karşı olmanın yanında, var olan totaliterliğe, kastçı feodal toplum düzenine, yeni şekillenmekte olan Burjuvazinin yönettiği bir harekettir (32. s). Rasyonel akıl, oluşumunu bu şartlara borçludur. Süreç, Weber'in dediği gibi bu salt orada duran bir büyüselliğin bozulması süreci değildir. Aksine yeni bir büyüselliğin içine girmesi, özel bir kullanıma alınması işidir. Şimdilerde bu büyüsellik hızla çözülmektedir ki Batı'nın teröre tutunmasının, etkinlik ve egemenliğini onunla götürmeye kalkışmasının sebebi de budur.

Araçsal aklın, en önemli aracı olan bilime dayanarak fazla değil yüz elli yıl önce insanlığa neler vadettiğini hatırlayalım: Bir kere irrasyonel ilkelerle çalışan din tarihe karışacak, en güzel şekliyle bilim onun yerini dolduracaktı. Sağlık sorunları kökten çözülecek, fert ve toplumlar daha sağlıklı bir hayat yaşayacaklardı. İmkânları paylaşma sorunu çözülecek, adaletli bir düzen içinde herkes mutlu olacaktı. Güvensizlik ortadan kalkacak, her haliyle güvenli bir ortam oluşacaktı. Çünkü bu paradigmaya göre, kavga ve gürültüler mutlu bir yaşama ortamının olmamasından kaynaklanır, bu ortam sorunu kökünden halledilmiş olacaktı. Tabii söylemeye gerek bile yok, bunun hiçbirisi gerçekleşmedi, dünya kan ve gözyaşına boğuldu; hastalıklar arttı, bölüşüm iyiden iyiye bozuldu. Modern öncesi toplumlarda acından ölen yoktu, şimdi rasyonel aklın yönlendirdiği aklın Batı dünyasının çirkin sömürüsüyle, kitlesel açlıktan ölüm olayları yaşanıyor. Rasyonel aklın öncelikli temsilcileri bunlara yardım etmeyi hiç düşünmüyorlar. Yardım edenler bütünüyle rasyonel akla teslim olmamış, hâlâ akledici bir akılla hareket edenlerdir.

Aslında rasyonel aklın sorunları yalnızca sonuçlarında değildir. Yapısal sorunları da gittikçe derinleşmektedir. Yazarımızın da belirttiği gibi, bunlardan birisi nesnellik krizidir (s. 48). O, ele aldığı konulara nesnel olarak yaklaştığını iddia etmekte ve meşruiyetini de büyük çapta bundan almaktaydı. Nesnellik; yansızlık, tarafsızlık veya iki taraflı, daha açık bir ifadeyle ortada olmak demektir. İyi de bu orta neresidir ve bunu kim belirlemektedir, referansı nedir? Bu mantığı, rasyonel aklın en somut verilerinden birisi olan bilim de taşımaktadır. O mutlak kabul ediliyor, her şey ondan referans alıyor, ama o, hiçbir şeyden referans alma ihtiyacını duymu- 
yor. Hâlbuki bilimin mutlak olmadığını, yanılabildiğini, kendine destek veren belli çevrelerce yanıltılabildiğini biliyoruz. 19. yüzyılda bilim adına ortaya konan verilerin bugün yüzde sekseninin yanlış olduğu kabul ediliyor. Bilimin bazı çevrelerce yanıltıldığı veya gerçeklere yan çizebildiği de biliniyor. Mesela bilimin kapitalizmin ürettiği mamaya yer açmak için yıllarca anne sütünün çocuğa zararlı olduğunu iddia ettiği hâlâ hafızalarımızdadır.

\section{Rasyonalitenin Problemleri}

Kendisi rasyonel aklın bir ürünü olan sosyoloji, geri dönüşlü olarak rasyonalizme ciddi desteklerde bulunmuştur. İçkinleştirmeyi toplum bağlamında yapan sosyolojiye göre doğrunun adresi toplumdur, onun konsensüsüdür. Eğer bireyin üstünde ve dışında bir kutsal kaynak varsa o, bunun diğer adı, toplumun ortak bilincidir. Durkheim'e göre bunun diğer adı da Tanrı'dır. Bu ortak bilincin genel geçer doğruluğunun önemi yoktur; doğru bulduğu şey doğru, iyi gördüğü şey iyidir; yani ahlaki olan da bu iyidir, Tanrı'nın emir ve tasarımları değil. Sosyoloji toplumun yüceltilmesine karşılık onu şekillendirilecek bir balmumu olarak görmektedir. Yani fert ve toplumların iradesini hiçe sayan bir toplum mühendisliği seçkinci rasyonalitesinin, bir başka deyişle sosyolojinin bir görevidir. İhtilal, devrim, inkılap 1789 hareketinden beri en çok ciro yapan kavramlardır. Darbeleri meşrulaştırma gerekçelerinin en önemlilerinden birisi ise kiliseye, yani dine karşı yapılmış olmalarıdır. Bu aşkın değer yıkıcılığı o kadar belirgindir ki, modernite kendisini tanıtırken bile bunu tüm olumsuzlukları gelenekselin altına sıralayıp kendisini bunların karşısına yerleştirerek yapmaktadir.

Bu alanı dolduran beşerî kökenli kültür ilahi mesajın yerine konmuştur. Cemil Meriç’in ifadesiyle, ilahi kökenli irfan kaldırılıp beşerî kökenli olan kültür onun yerini almıştır. Kültürün her alanı da geri dönüşlü olarak rasyonalizm yoluyla yeniden inşa edilmiştir. Nakıb el-Attas'ın ifadesiyle bir taraftan sekülerize edilirken diğer yönden desakramentalize sürecinden geçirilmiştir. Mesela yazarımızın da ayrıntılı olarak üzerinde durduğu gibi sanat bunun tipik örneklerinden birisidir (s. 102).

Rasyonel aklın doğurduğu olumsuz sonuçlardan birisi, şüphesiz manevi nitelikli otoritenin yerine salt sırf madi nitelikli iktidarı ortaya çıkarmış olmasıdır. Buna göre, artık insanın yeryüzü ile ilişkisi bile kadim kültürlerdeki gibi bir emanet ve emanetçi ilişkisi değil, bir egemenlik sorunudur. Tabiat, mutlaka üstesinden gelinip alt edilmesi gerekli bir vahşi varlıktır. Doğanın kontrol altına alınması Tanrı'dan bir emanet alma değil, ondan koparılmış bir egemenlik hakkıdır (!). Dolayısıyla her şey farklı algılanır hale gelmiştir. Mesela kar yağışı kontrol dışı olduğu için istenmeyen olağanüstü bir olaydır ve hatta bu çoğu kere bir felaket haberi olarak verilir. 
Artık iktidar duygusunu destekleyecek pek çok etken vardır. Şerif Mardin'in ifadesiyle, insanlık tarihi boyunca erdemlilik için kontrol altında tutulagelen deamonik (insanın içindeki şeytani) yapı serbest bırakılmış, lağım patlamışçasına ortalığı kazurat kaplamıştır. İktidar hırsı, arzu, cinsellik, çıkarcılık, sömürgecilik, kaba kuvvet kullanma vb. hiçbir anormallik görülmeden mevcut hayat anlayışının gerekleri sayılmıştır. İktidarın da en önemli araçlarından birisi olan arzu pek çok şeyin belirleyicisi olup çıkmıştır. Mesela bu çizgiye çok uzak olan sanat bile salt estetiksel olmaktan çıkmış, haz almaya yönelik bir hal almıştır. Onun için de sanat ile estetik arasında bir ayırım yapma zorunluluğu ortaya çıkmıştır.

Rasyonel aklın doğurduğu diğer önemli bir sorun, manevi nedensellik diyebileceğimiz hikmetin ortadan kaldırılıp yerinin işlevsellikle doldurulmuş olmasıdır. Yazarımız bu arada katılmadığım bir yargıya ulaşmış, mevcut sanat anlayışının, sanatın işlevselliğinin üstünü örttüğünü söylemektedir (s. 126). Hâlbuki tam aksine mevcut sanat anlayışı, deruni estetiğin üzerini örterek sanatı işlevsel hale getirmiştir. Sanatın haz verici, tahrik edici olması, sanata özgü ruhsal bir anlam değil, bedensel çıkara, tabi aynı zamanda iktidara yönelik bir sonuçtur. Bu arada belirtmeliyiz ki din, sanat ve ahlak işlevsellikle ölçülemez. Dinî eylemler doğrudan günlük bir işlevi yerine getirmediği gibi, pek çok ahlaki tutum işlevsellik açısından aptallık olarak nitelendirilebilir. Sanatın değeri de hiçbir zaman, yarayışlı ve kullanışlı olmasına bağlı değildir. Ne var ki pek çok beşerî olguda olduğu gibi sanatın toplumsallığı da yapılan işlerin meşruiyet kılıfına dönüştürülmüştür. Bana göre, sosyolojinin bir klişe haline getirdiği toplumsallık söylemi sorgulanmalıdır. Bir şeyin topluma indirgenmesiyle onunla etkileşmesi faklı düzeylerde süreçlerdir. Elbette hemen her şey toplumdan bir referans bulabilir, karşılıklı olarak etkiler ve etkilenir. Toplumsal olarak adlandırılan bazı oluşumlar çaktırmadan yapılan diktelerdir.

Yukarıdaki söylenenlerden de anlaşılacağı üzere din, ahlak ve sanatın dünyevi aklın emrine verilmesi ciddi hatalar doğurmaktadır. Artık bunların doğru olarak anlaşılması bile (vahiy ve hikmetle değil, sadece zekâ ile aydınlanmış), alanı olmayan rasyonaliteden beklenmekte, onun kanaatine sunulmaktadır. Akletmenin dışında kalan bu süreçten elbette sağlıklı bir sonuç beklenemez. Esasen bir serbest piyasa mantığı içinde türetilen piyasa din anlayışlarının aynı dine inananları paramparça yapması bu yargımızı doğrulamaktadır. Din birleştirmek için vardır, parçalamak için değil. Ama günümüzde yaygınlaşan rasyonel dinî söylem, müntesiplerini sürekli bölmektedir. Demek ki akletme üzerine kurulmayan rasyonalist din anlayışları insanları karşı karşıya getirmektedir. Çünkü herkesin bir rasyonalitesi vardır ve en rasyonalist (bir başka deyişle en mantıklı) olanı kendisininkidir. Yine rasyonel ahlak ancak bir çıkar ahlakı olabilir. Bu yargımıza tam uygun olarak Aydınlanma'nın ahlak felsefecilerinden olan Mandewil, ahlakı bencilliklerimizin kesişme noktası olarak tanımlıyordu. 


\section{Rasyonalitenin Özgürlük Aldatmacası ve Vahiy}

Modernitenin rasyonel akılla hedeflediği şey, dünyayı ve toplumu hep yeniden kurgulamaktır. Bunun için pek çok araç türetmiştir. Bir yegâne rasyonalite üretimi değilse de teknoloji ve sanayi bu araçsal yapılardan birisidir. Bu yapılar ve dayandırılan ilkeler birbirleriyle çelişmektedir. Mesela özgürlük teknoloji ile bağdaşmaz. Esasen özgür olmak özgür olduğunu düşünebilmeye indirgenmiştir. Burada insan havaya atılan taşa benzemektedir. Spinoza'nın benzetmesiyle eğer, insan gücüyle havaya fırlatılan ve çekim gücüyle yere düşen taş düşünebilseydi "Kendim çıktım, kendim indim." derdi. Rasyonalitenin akıntısına kapılmış ve yön verici mutlak ilkelerle çalışmak zorunda olan insan da bu taş misali özgürce düşündüğünü sanmaktadır. Mesela dinin gereği üzerine düşünceleri özgürce düşünmenin bir sonucu değildir, yüklenmiş ezberlerdir. Ama o her şeye rağmen bu gizil esaretinden memnun ve mutludur. Çünkü burada bir başka açıdan bakma imkânı bulamayan insanı tatmin edecek pek çok şey sunulmaktadır. Bilgiye yüklenen olağanüstü işlev bunların başında gelmektedir. Mesela bilgi toplumu kandırmacası bunlardan sadece birisidir. Mevcut toplumları niteleyen şey bilgi değil, diyeti bir hayli yüksek konfor, tüketimin verdiği hazdır. Kitleler için bilgi kırıntılarının fazlaca bir önemi yok. Bir gecede bayatlayan, tüketilen malumatın toplumun doğasını oluşturduğunu sanmak en hafif ifadesiyle safdilliktir.

Aklın rasyonalitenin göreceliliğinden kurtulabilmesi için vahyî bilgiye ihtiyaç vardır. Çünkü hak, doğruluk, adalet ve bunların gerçekleştirim yolu aklın toplumsal şartlardan çıkarabileceği bir şey değildir, orada duran verilmiş erdemlerdir. Modern dünyanın yaşadığı epistemolojik sorunların nedeni bundan kopuk olmasıdır. Doğru ve soylu bilgi, sırf akli bir kurgu değildir. Çünkü akıl yeteneğinin sınırları vardır. Batı felsefesi (mesela Kant) bunun sınırlarının deney verileri olduğunu söylemekte ve deney verilerinin akla eşlik etmediği yerde aklın bize doğru bir bilgi verme imkânı bulunmadığını belirtmekteydi. Çünkü gerçekten de deney verilerinin eşlik etmediği bilgi bir hayal, bir fantezidir. Ancak doğru düşünebilen aklın sınırı sadece aşağıdaki deney verileri değildir. İnsanın özlük alanı için bu sınırı açacak başka desteklere ihtiyaç vardır ki bu ilahi mesajlardır. Bu aynı zamanda nominal bilginin eksiğini giderecek yegâne yoldur.

Aklın çözümü olan akledici akıl, Allah'ın yardımıyla gerçekleşen bir şeydir. Gerçekten insan dünyaya öylece bırakılıvermiş bir varlık değildir. Buraya bir donanımla yerleştirilmiş, araçsal aklın yanıltıcılıklarına karşı rehberler gönderilmiştir. Kư’an'da "Bu kitap, dünya kuyusuna düşmüş insana, tutunup kurtulması için Allah'ın semadan sarkıttığı bir iptir." buyurmaktadır. Akletme, kalbî duyumlar ve vahyî bilgi bileşkesinde gerçekleşen bir süreçtir. Esasen uzunca bir zaman bilme, 
inanma, değer verme, eylemde bulunma gibi insani süreçler bir eksende birleşiyordu ve bunun adı din idi. Ancak bu din, bizim şimdi kullandığımız anlamda bir sırf inanma alanı değildi. Bunlar uzun zaman içerisinde bir ayrışma yaşadı. Bilme, eksene oturdu ve dinin yerini aldı. Din de inanma alanının genel adı oldu. E. Gellner'in dediği gibi, bu yeni algıya göre Tanrı da bu süreçlerin tamamının değil, bu özel din pramidinin hâkimi idi. Bu arada akıl, yalnızca bilginin aracı haline geldi. Dayanaklarından koparıldıkları için sırf insani süreçler sıkıntıya düşmekle kalmadı, bu kopukluk akli yeteneği korunaksız hale getirdi, kendisi rahatça kurgulanabilen bir araçsal yapıya dönüştü.

Eser genel olarak anlamlı ve tutarlı. Eserin tezi olan dünyevi akıl ve sorunları üzerinde yeterince durulmuş, ama buhran beklendiği kadar açıklanamamış. Bu söz konusu bunalım yeni çalışmalar gerektiriyor. O güzel ifade şeklinin yanında yer yer bir dağınıklıktan da söz edilebilir. Bu durum kendisini asıl tezle bağlantı kurmalarda göstermiş. Mesela muhafazakâr sanatla dünyevi aklın bağlantısının nasıl kurulduğu yeterince açık değil. Sonuç ve değerlendirme bu anlamlı tezi daha iyi vurgulayacak şekilde olabilirdi.

Kanaatimce dünyevi akıl, iki yandan hareketle oluşturulmuştur: Birincisi, oluşan toplumsal şartların iticiliğinde bir dünyeviliğin kurulması; ikincisi, insan zihninin aşkın bağlardan koparılmasıdır. Esasen ilahi mesajla bağlantı iradi bir iştir. İnsan bu çabayı göstermediği zaman söz konusu yetenek sadece dünyayı algılayan bir zekâya, elimizdeki metnin nitelemesiyle dünyevi akla dönüşür. Modern kültür gelişmesinde olan da budur. Sığ bir nedensellik süreci içinde mahsur kalıp salt insani bir olgu olmaktan çıkan akıl, sadece kendi hayatını kuran zoolojik bir yetenek (zekâ) haline gelmiştir. Özgürlük için yola çıkan akıl, gerçekten özgürlügünü yitirerek etkin çevrelerin emir eri olmuştur. Geniş kitleler ise özgür düşündüklerine inandırılmışlardır. Bütün bunlardan sonra akıl denen insani yetenek gerçekten hastadır ve bir bunalım yaşamaktadır. Ne var ki hasta pek çok ruhi hasta gibi hastalığının farkında değildir. Kirliliğin, kendisinin farkına varamayışı hatta bunu bir zenginlik sayıp temizliğe ihtiyaç duymaması gibi. 